\title{
EEG Abnormalities and Convulsions in Juvenile Diabetes Mellitus
}

\author{
D.L. Keene, K. Metrakos, M. Belmonte, G.V. Watters and S. Singer
}

SUMMARY: The clinical and EEG findings were reviewed for 270 juvenile children from the Montreal Children's Hospital Diabetic Clinic in an attempt to correlate the EEG findings at the onset of diabetes mellitus with the future risk of having a convulsion with a hypoglycemic reaction. Compared to a non-diabetic control population, the number of epileptiform EEG abnormalities was significantly increased in the initial EEG of diabetic patients who later had a hypoglycemic convulsion. The initial epiliptiform EEG did not help to differentiate those diabetics with recurrent hypoglycemic induced convulsions from diabetics who would have only a single convulsion.

RÉSUMÉ: Nous avons étudié, chez 270 enfants de la clinique de diabète du Montreal Children's Hospital, les données cliniques et électroencéphalographiques afin de faire la corrélation entre les données de l'EEG au début du diabète et le risque d'avoir plus tard une convulsion lors d'une réaction hypoglycémique. Le nombre d'anomalies à l'EEG initial était significativement plus élevé chez les diabétiques qui éventuellement devait avoir une convulsion hypoglycémique que dans la population non diabétique témoin. L'EEG initial ne permet cependant pas de distinguer ceux parmi les diabétiques qui devaient avoir des convulsions hypoglycémiques répétées des diabétiques qui n'auront qu'une seule convulsion.

Can. J. Neurol. Sci. 1983; 10:198-199

Almost every diabetic child will experience a hypoglycemic episode at some stage of the illness. The majority of these reactions are mild and easily resolved by the administration of food or sugar containing compounds. In a few children, these reactions may proceed to loss of consciousness and a convulsion. With increased emphasis being placed on precise diabetic control in an attempt to prevent long-term complications, the risk of hypoglycemic reactions associated with convulsions will probably increase. The purpose of this paper is to present the findings of a study undertaken at the Montreal Children's Hospital to assess the role of the EEG early in the course of diabetes to help identify those patients at risk of having a hypoglycemic convulsion.

\section{METHODS}

The EEG's and clinical records were reviewed for 270 diabetic children being followed at the Diabetic Clinic in the Montreal Children's Hospital. EEG's were ordered as part of the initial assessment of diabetic children in the Clinic. They were done within the first weeks of diagnosis regardless of the neurological state of the patients. All patients were normoglycemic at the time of the recordings. These records were done on either an eight or sixteen channel Grass EEG machine. Both "referential" and "bipolar" montages were utilized along with intermittent photic stimulation and hyperventilation (where age permitted).

The EEG's were reviewed without prior knowledge of seizure history. They were divided into normal and abnormal groups. The abnormal EEG's were further classified according to the major abnormality. Background activity was assessed visually. For a waveform to be considered epileptiform (i.e., spike or paroxysmal sharp slow wave), it had to meet the criteria established by Gloor (1975).

An independent retrospective review of the charts for these diabetic children was done to identify those with a history of convulsions. Patients with seizure disorders (other than atypical febrile seizures) prior to the onset of their diabetes mellitus were excluded. Correlation between the seizure history and original EEG patterns was then made. Control EEG data for this study was obtained from previously published data(Metrakos et al, 1961).

\section{Results}

Two hundred and seventy patients met the criteria for entry into this study. Fifty (19\% of the total population under study) had one or more convulsions after the onset of diabetes. Fortyone of these fifty patients (15\% of the total population under study) had convulsions with a hypoglycemic event. Recurrent hypoglycemia occurred in $80 \%$ of these forty-one patients.

The initial EEG patterns of children with juvenile diabetes were compared to those of a non-diabetic control group (Table 1). Abnormal EEG's occurred more frequently in the diabetic group. The most frequent abnormality was a nonspecific diffuse disturbance of cerebral activity consisting of increased theta

Table 1: Initial EEG findings in children with diabetes mellitus and in non diabetic control population

\begin{tabular}{lccc}
\hline \hline & $\begin{array}{c}\text { Total Diabetic } \\
\text { Group (\%) } \\
\mathbf{N}=\mathbf{2 7 0}\end{array}$ & $\begin{array}{c}\text { Non Diabetic } \\
\text { Controls (\%) } \\
\mathbf{N}=\mathbf{1 3 8}\end{array}$ & $\mathbf{P}$ \\
\hline Type of EEG & 48.0 & 77.5 & $\mathbf{0 . 0 0 0 1}$ \\
Normal & 34.0 & 10.9 & $\mathbf{0 . 0 0 0 1}$ \\
Diffuse Nonspecific & 1.9 & 4.4 & $\mathbf{0 . 2 5}$ \\
Focal Sharp Wave & & & \\
Generalized Paroxysmal & 7.6 & 1.5 & $\mathbf{0 . 0 2 5}$ \\
Sharp Slow Wave & 6.3 & 5.8 & 0.8 \\
Generalized Spike Wave & 16.0 & 10.1 & 0.15 \\
Total Epileptiform & & & \\
\hline
\end{tabular}


activity and poor background organization. Generalized paroxysmal sharp slow waves are also more common in the diabetic group. Generalized spike wave discharges occurred with about equal frequency in both groups.

When the initial EEG's of diabetics who later had a convulsion were compared to the EEG's of the nondiabetic control group, there was a significant increase in the number of epileptiform EEG abnormalities in the group with convulsions (Table 2). The EEG's of the diabetics with hypoglycemic induced convulsions were compared to those of the diabetics whose convulsions were independent of hypoglycemia (Table 3). Generalized spike wave bursts occurred more often in patients with convulsions not associated with hypoglycemia while generalized paroxysmal sharp slow waves were more common in the group with hypoglycemic related convulsions.

There was no significant difference in the initial EEG pattern for patients who subsequently developed recurrent hypoglycemia related convulsions compared to those who had only a single seizure.

\section{DISCUSSION}

Hypoglycemia may be associated with minor symptoms such as tremulousness, cold sweats, twitches, headaches and confusion, or with major neurological signs and symptoms (e.g., delirium, hypothermia, brainstem dysfunction, strokelike illness and focal or generalized seizures). The extent of neurological involvement for a given level of hypoglycemia is not the same for all diabetic children. The exact mechanism of this variation in response is not fully understood.

On the basis of clinical findings and EEG patterns in 257 diabetic children, Eeg-Olofsson (1977) postulated that some individuals have a primary diabetic encephalopathy with an

Table 2: Initial EEG findings in diabetics who had seizures and in nondiabetic control groups

\begin{tabular}{lccc}
\hline \hline & $\begin{array}{c}\text { Diabetic Group } \\
\text { with Seizures } \\
(\%)\end{array}$ & $\begin{array}{c}\text { Control Group } \\
(\mathbf{\%})\end{array}$ & \\
Type of EEG & $\mathbf{N ~ 5 0}$ & $\mathbf{N ~ 1 3 8}$ & $\mathbf{P}$ \\
\hline Normal & 44 & 77.5 & $\mathbf{0 . 0 0 1}$ \\
Diffuse Nonspecific & 30 & 10.9 & 0.001 \\
Focal Sharp Wave & 0 & 4.4 & $\mathbf{0 . 0 3 0}$ \\
Generalized Paroxysmal & & & \\
Sharp Slow Wave & 14 & 1.5 & $\mathbf{0 . 0 0 1}$ \\
Generalized Spike Wave & 12 & 5.8 & $\mathbf{0 . 1 0}$ \\
Total Epileptiform & 26 & 10.5 & $\mathbf{0 . 0 0 1}$ \\
\hline
\end{tabular}

increased tendency to develop neurological symptoms in response to hypoglycemia. He thought this sensitivity was dependent upon age and cerebral maturation as well as prenatal and postnatal factors.

Our study, like that of Eeg-Olofsson, showed a relationship between EEG findings and the major neurological signs. Unlike previous studies (Eeg-Olofsson, 1977; Eysold, 1966; Gilhaus et al, 1973; Haumont et al, 1979) ours was the first attempt to correlate the EEG pattern at the time of onset of diabetes mellitus with the risk of developing hypoglycemic convulsions in the future. Our data showed a strong correlation between the occurrence of hypoglycemic seizures and paroxysmal abnormalities. In the initial EEG, diabetic children in whom the EEG showed a generalized paroxysmal sharp slow wave disturbance were more likely to have subsequent hypoglycemic convulsions than other diabetic children. Children in this category should be advised to look for minor signs such as twitches and focal seizures in order that extra snacks may be provided at bedtime after active days or when the blood sugar is low to avoid severe noctural hypoglycemia. Use of home blood glucose monitoring can be useful in this situation.

Our experience with anticonvulsant drugs in patients who have had hypoglycemic induced convulsions has been limited. Anticonvulsants have been reserved for patients in whom attempts to prevent hypoglycemia have failed. To prevent recurrent seizures, phenobarbital, dyphenylhydantoin, carbamazepine and sodium valproate have been used in these cases with success. Anticonvulsants are not recommended for patients with an epileptiform disturbance on the EEG with no history of convulsions.

\section{REFERENCES}

Eeg-Olofsson, O. (1977), Hypoglycemia and neurological disturbances in children with diabetes mellitus, Acta Paediatr. Scan. Suppl. 270:91.

Eysold, R. (1966), Cerebrale storungen bei diabettes mellitus und electroencephalographische untersuchungen bei diabetischen kinders, Monatschr. Kinderheilkd 114:94.

Gilhaus, K.H., Daweke, H., Lulsdorf, H.G., Sachsse, R. and Sachsse, B. (1973), EEG - Vevenderungen bei diabetischen kindern, Deut. Med. Wschr. 98:1449.

Gloor, P. (1975), Contributions of electroencephalography and electrocorticography to the neurosurgical treatment of the epilepsies, Adv. of Neurol., chapter 5, pp. 59-107.

Haumont, D., Dorchy, H., and Pele, S. (1979), EEG abnormalities in diabetic children, Clinical Pediatrics 18:750.

Metrakos, D. and Metrakos, J.D. (1961), Genetics of convulsive disonders, II Genetics and electroencephalographic studies in centrencephalic epilepsy, Neurol. 11:474.

Table 3: Initial EEG findings in diabetics with hypoglycemic-induced convulsions and in diabetes with convulsions not associated with hypoglycemia

\begin{tabular}{lcccc}
\hline \hline & $\begin{array}{c}\text { Frequency for the } \\
\text { Total Diabetic Group } \\
\text { with Convulsions } \\
\mathbf{N = 5 0}\end{array}$ & $\begin{array}{c}\text { Frequency In Patient Group } \\
\text { with Non Hypoglycemia } \\
\text { Related Convulsions } \\
\mathbf{N = 9}\end{array}$ & $\begin{array}{c}\text { Frequency In Patient Group } \\
\text { with Hypoglycemic } \\
\text { Relation convulsion } \\
\mathbf{N}-\mathbf{4 1}\end{array}$ \\
\hline Nype of EEG & $44 \%$ & $44 \%$ & $39 \%$ \\
Normal & $30 \%$ & $22 \%$ & $29 \%$ \\
Fiffuse Nonspecific & 0 & 0 & 0 & 0.3 \\
Gecal Sharp Wave & $14 \%$ & $11 \%$ & $24 \%$ & $\mathbf{7 \%}$ \\
Sharp Slow Wave & $12 \%$ & $22 \%$ & $31 \%$ & 0.001 \\
Generalized Spike Wave & $26 \%$ & $33 \%$ & 0.001 \\
Total Epileptiform & & & 0.900 \\
\hline
\end{tabular}

